\title{
An unusual case of both anterior and posterior cruciate avulsion fracture at the insertional site in an isolated injury of skeletally mature knee: A case report
}

\author{
Abhay H Kerketta, Parvez A Afzal, David V Rajan
}

Abstract: In children, ACL avulsion fractures are common as compared to adults who have midsubstance tears. [1] 40 - $50 \%$ cases of isolated PCL avulsion occurs at tibial insertion site as compared to femoral origin or midsubstance tear. [2] Avulsion fractures as compared to intrasubstance tears can be treated operatively or nonoperatively with favourable results. [3] Isolated ACL and PCL avulsion injury in a skeletally mature knee is rare.

Keywords: ACL avulsion, PCL avulsion

\section{Introduction}

The knee is particularly predisposed to complex injuries after trauma because of numerous tendinous, ligamentous and meniscal attachments. Isolated ACL or PCL avulsion fractures are common knee injuries especially in adolescent age groups. Occurrence of both with the same injury is rare entity. These fractures often are unremarkable at standard radiography, which is typically the first imaging modality done in these cases. Avulsion of posterior cruciate ligament of the tibia are rare and are difficult to visualize at radiography. CT and MR imaging can display the fracture site to greater advantage.[4,5] We present one such case to increase the awareness of orthopedic surgeons regarding coexistence of both cruciate avulsion in isolated knee injury of skeletally mature individual.

\section{Case Report}

A 29 year old male presented to the emergency department following a motor vehicular accident on 4 July 2013. He met with a collision while driving his two wheeler at a speed of $50 \mathrm{kmph}$ with another four wheeler and was thrown off from the vehicle. He sustained no other injuries except his right knee. On clinical examination, we found that he had significant effusion in the affected knee. He complained of pain in the knee, especially during active and passive extension of knee. There was tenderness at the posterior aspect of the knee. No neurovascular deficit was found. The knee was stable under varus and valgus stress. Both anterior and reverse lachman were positive. Under aseptic conditions the tense effusion was aspirated and $80 \mathrm{ml}$ of blood was evacuated. Xrays taken at the emergency department showed avulsion fracture of both ACL and PCL as shown ( Fig 1a \& 1b).
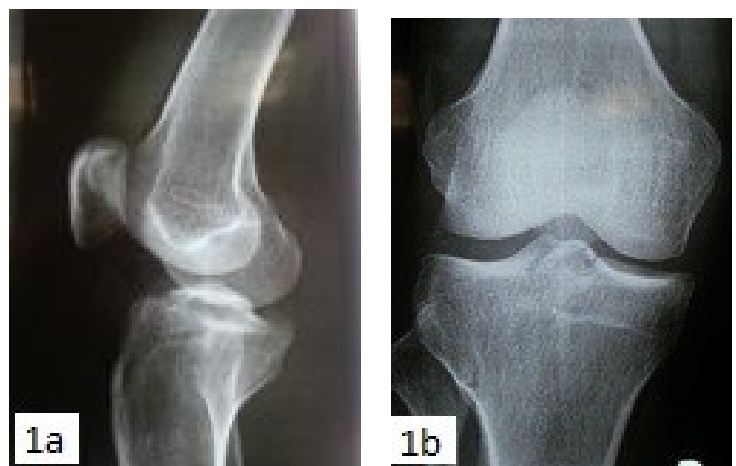

Fig 1 a \& b. Xrays showing avulsion of ACL and PCL from tibial insertion site

Right knee magnetic resonance imaging (MRI) was done which showed incomplete avulsion fracture of ACL an PCL tibial insertions. ( Fig 2a,2b,2c). There was no intrasubstance tear in either of the cruciates. The medial and lateral collateral ligaments were normal. No meniscal tear was found. Posterolateral complex(PLC) was preserved. As the patient was a low demand person and avulsions being undisplaced, we decided to manage the patient nonoperatively. 

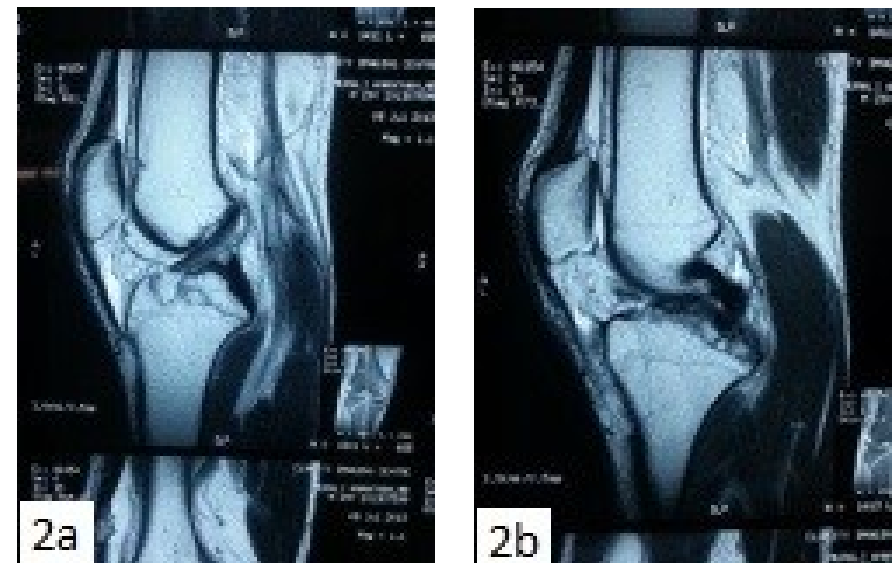

Fig 2a, 2b. : MRI picture showing avulsion of ACL from tibial insertion site. The fibres are in continuity and unremarkable. PCL avulsion fracture with buckling of PCL fibres seen, however with no intrasubstance tears.

\section{Discussion}

In our literature survey we came across only one case report of ACL and PCL avulsion fracture that too in a polytraumatised adolescent patient who was managed operatively [6] Our case is different, as our patient was skeletally mature and had an isolated knee injury. Xrays followed by MRI were done to confirm our diagnosis. Conservative treatment was opted as it was Type 1 undisplaced ACL and PCL avulsion fracture. Regular clinical and radiological evaluation was done. Patient was kept nonweight bearing in a knee brace for 4 weeks. Progressive weight bearing and knee movements began at 4-6 weeks duration. He achieved full knee bending by 8 weeks. Xray and CT scan done at 20 weeks showed evident union of ACL and PCL avulsion fractures.( Fig 3a, 3b; Fig 4a, 4b, 4c)
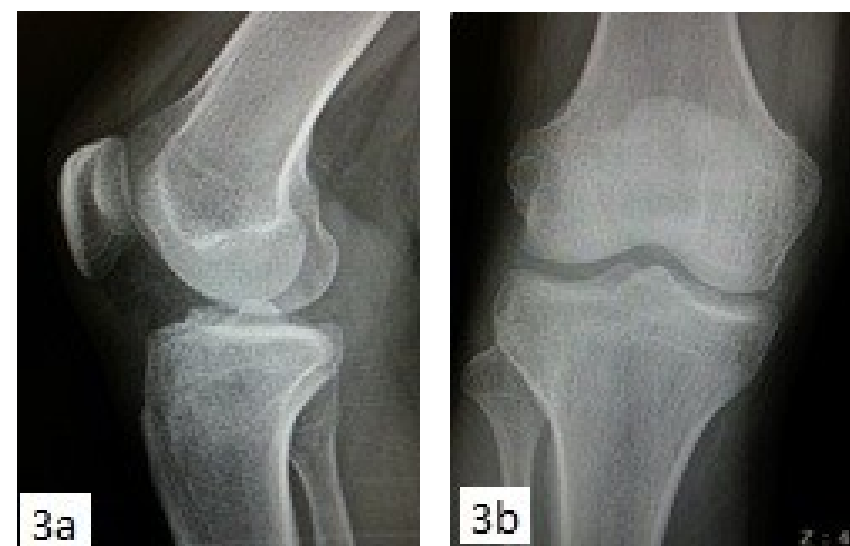

Fig 3a, 3b : Xray at 20 weeks post injury showing healed avulsion fracture
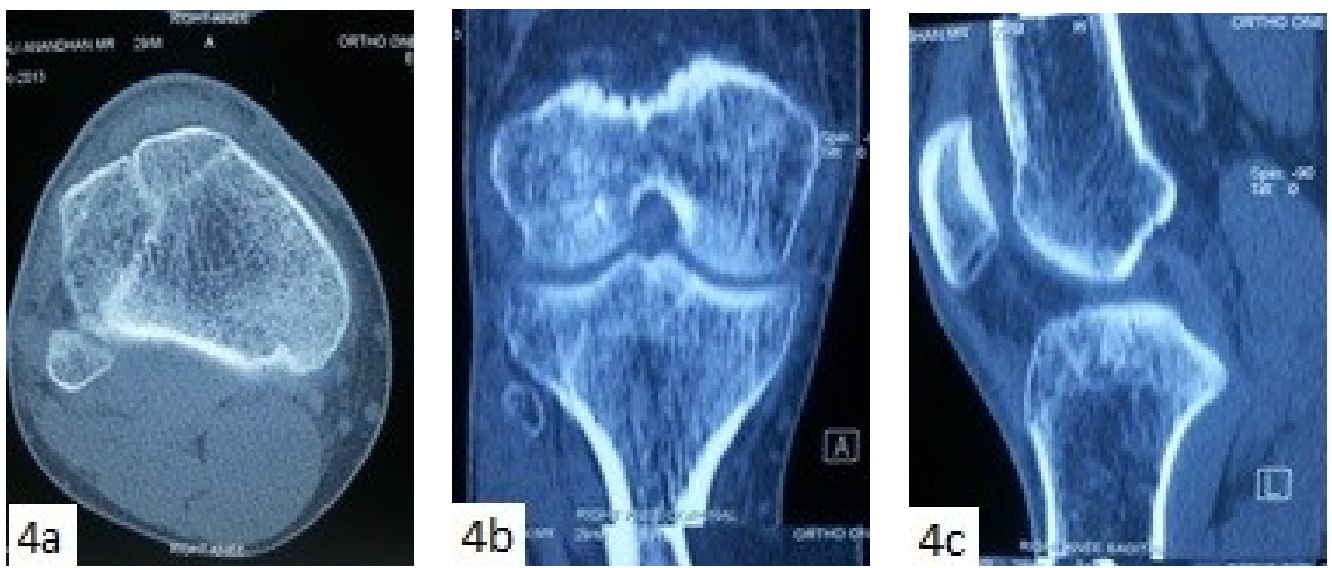

Fig 4a, 4b, 4c : CT scan at 20 weeks post injury showing healed avulsions. 
Clinical outcome of the patient was satisfactory at the end of 20 week (Fig 5a,5b). Early operative reconstruction of avulsion fractures of ACL and PCL are easy to perform and the results are better $[7,8,9,10]$ However for an undisplaced avulsion fracture, we suggest nonoperative modality as advocated for isolated ACL / PCL avulsion fractures. Flexion (15-20 deg ) casting may not be necessary as previously advised. [11]
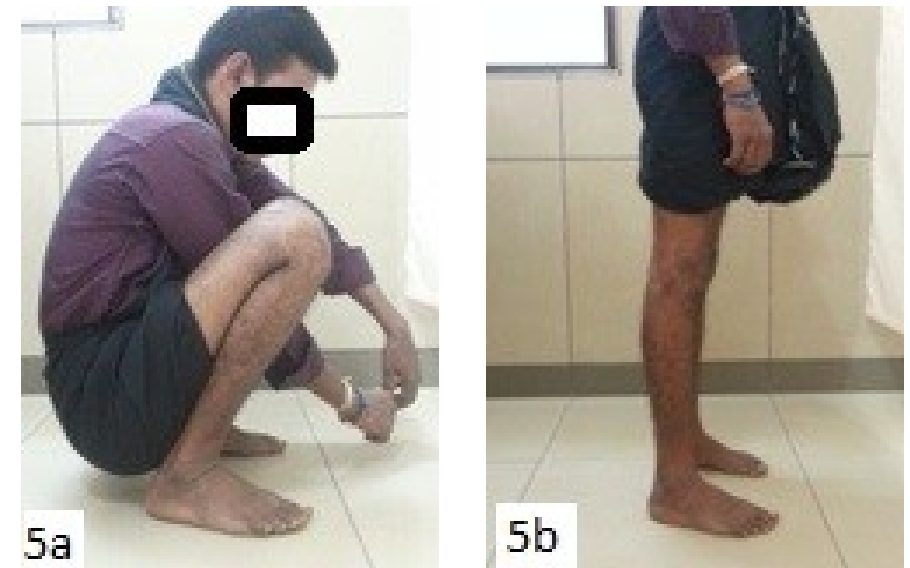

Fig 5a,5b : Clinical picture showing full ROM achieved after conservative treatment at 20 weeks

\section{Conclusions}

Isolated ACL and PCL avulsions are rare and can occur in skeletally mature individuals. All avulsions do not need surgical intervention. We suggest that undisplaced ACL and PCL avulsions can be managed conservatively with good functional outcome. But conservative method may not be the ideal treatment of choice for severely displaced avulsions. Hence, proper clinicoradiological assessment is a must before offering right treatment modality to the patient.

\section{Consent}

Written informed consent was obtained from the patient for publication of this case report and the accompanying images.

\section{References}

[1]. Remer EM, Fitzgerald SW, Friedman H , Rogers LF , Hendrix RW, Schafer MF, Anterior cruciate ligament injury : MR imaging diagnosis and patterns of injury. Radiographics 12, 1992, 901-915.

[2]. Hunter JC, Chapman JR, Isolated avulsion of the posterior cruciate ligament : an uncommon dashboard injury. AJR Am J Roentgenol 164, 1995, 1190.

[3]. White EA, Patel DB, Matcuk GR, Forrester DM, Lundquist RB, Hatch GF 3 rd, Vangsness CT, Gottsefen CJ, Cruciate ligaments avulsion fracture : Anatomy, biomechanics, injury patterns and approach to management. Emerg Radiol. 20(5), 2013, 429-40.

[4]. Capps GW, Hates CW, Easily missed injuries around the knee. Radiographics 14, 1994,1191-1210.

[5]. Delzell PB, Schils JP, Recht MP, Subtle fractures about the knee: innocuous appearing yet indicative of significant internal derangement. AJR Am J Roentgenol 167, 1996, 699-703.

[6]. Calpur OU , Copuroglu C, Ozcan M, Avulsion fracture of both anterior and posterior cruciate ligament tibial insertion. Knee Surg Sports Traumatol Arthrosc 10(4), 2002, 223-225.

[7]. Cole BJ, Harner CD, The multiple ligament injured knee. Clin Sports Med 18, 1999, 241-162.

[8]. Dickob M, Mommsen U, Fracture of the proximal tibia and knee ligament injuries. Unfallchirurgie 20, 1994, 88-93

[9]. Holzach P, Matter P, Complex internal knee lesions- diagnosis indications and timing. Ther Umsch 50, 1993, $500-508$.

[10]. Limbird TJ, Garside WB, Richards DB, Early operative reconstruction of severe ligamentous knee injuries in patients with multiple trauma. J South Orthop Assoc 6, 1997, 88-92.

[11]. Eric A, Dakshesh B Patel, George R Matcuk, Deborah M Forrester, Ryan B Lundquist, George F, Rick Hatch III, C Thomas Vangsness, Christopher J Gottsegen, Cruciate ligament avulsion fracture: Anatomy, biomechanics, injury patterns and approach to management. Emerg Radiol Oct 20(5), 2013 , 429-40. 